\title{
Assessment of yeast viability under hyperbaric conditions through a modeling approach
}

\author{
João AP Coutinho, ${ }^{1}$ Isabel Belo, ${ }^{2}$ Eugénio C Ferreira ${ }^{2}$ and M Alice Z Coelho ${ }^{3 *}$ \\ ${ }^{1}$ CICECO, Departamento de Química, Universidade de Aveiro, 3810-193 Aveiro, Portugal \\ ${ }^{2}$ Centro de Engenharia Biológica, Universidade do Minho, 4710-057 Braga, Portugal \\ ${ }^{3}$ Departamento de Engenharia Bioquímica, Escola de Química, UFRJ, 21949-900 Rio de Janeiro, Brazil
}

\begin{abstract}
The effect of pressure (0.1-1.5 MPa) and oxygen concentration on the growth and viability of Saccharomyces cerevisiae was studied. Cell viability was assessed through the Methylene Blue staining method and the percentages of viable and non-viable cells were estimated using digital image processing. A model taking into account cell viability was developed and used to describe the measured data. The model reveals the opposing effects between oxygen availability and the baric and oxidative stresses present on the system and can successfully describe not only the traditional biomass-product-substrate (X-P-S) evolution but also the ratio of viable cells with time. It is shown that cell viability in general is not constant during the experiments but strongly depends on the environment.
\end{abstract}

(c) 2005 Society of Chemical Industry

Keywords: modeling; digital image processing; cell viability; yeast

\section{NOTATION}

a Contact area

EtOH Ethanol $\left(\mathrm{g} \mathrm{dm}^{-3}\right)$

$f \quad$ Fugacity $(\mathrm{MPa})$

$F \quad$ Flow rate $\left(\mathrm{dm}^{3} \mathrm{~h}^{-1}\right)$

$H_{i} \quad$ Henry's constant (dimensionless)

$K_{\mathrm{D}} \quad$ Specific rate of transformation of viable cells into non-viable cells $\left(\mathrm{h}^{-1}\right)$

$K_{\mathrm{L}} \quad$ Mass transfer coefficient

$K_{\mathrm{S}} \quad$ Substrate saturation constant $\left(\mathrm{g} \mathrm{dm}^{-3}\right)$

$N_{\mathrm{A}} \quad$ Gas transfer rate $\left(\mathrm{g} \mathrm{dm}^{-3} \mathrm{~h}^{-1}\right)$

$P \quad$ product concentration $\left(\mathrm{g} \mathrm{dm}^{-3}\right)$

$P_{\mathrm{R}} \quad$ Pressure $(\mathrm{MPa})$

$t \quad$ Time (h)

$S \quad$ Substrate concentration $\left(\mathrm{g} \mathrm{dm}^{-3}\right)$

$S_{\mathrm{f}} \quad$ Substrate concentration in the feed stream $\left(\mathrm{g} \mathrm{dm}^{-3}\right)$

$V \quad$ Reactor volume $\left(\mathrm{dm}^{3}\right)$

$x_{\mathrm{O}_{2}} \quad$ Oxygen concentration on the liquid phase $\left(\mathrm{g} \mathrm{dm}^{-3}\right)$

$x^{*} \quad$ Concentration on the liquid phase in equilibrium with the gas phase $\left(\mathrm{g} \mathrm{dm}^{-3}\right)$

$X_{\mathrm{t}} \quad$ Total cell concentration $\left(\mathrm{g} \mathrm{dm}^{-3}\right)$

$X_{\mathrm{V}} \quad$ Viable cells concentration $\left(\mathrm{g} \mathrm{dm}^{-3}\right)$

$X_{\mathrm{NV}} \quad$ Non-viable cells concentration $\left(\mathrm{g} \mathrm{dm}^{-3}\right)$

$y_{\mathrm{O}_{2}} \quad$ Oxygen concentration on the gas phase (mol\%)

$Y_{\mathrm{P} / \mathrm{X}}$ Product (ethanol) to biomass yield coefficient $\left(\mathrm{g} \mathrm{g}^{-1}\right)$
$\begin{array}{ll}Y_{\mathrm{X} / \mathrm{S}} & \text { Biomass to substrate yield coefficient }\left(\mathrm{g} \mathrm{g}^{-1}\right) \\ \gamma & \text { Cell viability (dimensionless) } \\ \mu_{\mathrm{R}} & \text { Real specific biomass growth rate }\left(\mathrm{h}^{-1}\right) \\ \varphi_{i} & \text { Fugacity coefficient (dimensionless) }\end{array}$

\section{INTRODUCTION}

Conventional models for biological reactors consider biomass as a homogeneous entity, making no distinction between the different states of the microorganisms. Yet behind this oversimplified picture lays a complex world of dead cells, others alive but not active, and yet others active and undergoing reproduction, all with different ages and sizes. Usually, the conventional approach does not quantify the cells on their different life stages and states since most of the process models used are non-structured, ie their kinetics are just a function of the total biomass concentration. Although this has been a successful approach to the correlation of fermentation macro-kinetic data, these models are unsatisfactory due to their poor description of the underlying biological complexity of systems dealing with stress phenomena, loss of cell viability, cell morphological changes, among others.

A number of structured models for various microorganisms, showing different levels of complexity and robustness to describe cell dynamics, either for a physiological or a morphological description have been recently proposed. ${ }^{1,2}$ So far few studies ${ }^{3-5}$ take into

\footnotetext{
* Correspondence to: M Alice Z Coelho, Dept Eng Bioquímica, Escola de Química, UFRJ, 21949-900 Rio de Janeiro, Brazil

E-mail: alice@eq.ufrj.br

Contract/grant sponsor: CAPES/GRICES

Contract/grant sponsor: CNPq (Brazil)

(Received 26 July 2004; revised version received 24 November 2004; accepted 24 November 2004)

Published online 22 April 2005
} 
account the loss of cell viability despite its importance on industrial productivity. The loss of cell activity in bioreactors is well known. It may be due to nutrient limitation or toxin accumulation in the broth, but other types of stress may also contribute to cell deactivation, such as pressure, ethanol, oxidative and/or mechanical stresses.

In this work, the loss of viability of Saccharomyces cerevisiae under barometric pressures ranging from 0.1 to $1.5 \mathrm{MPa}$ and different gases (air, oxygen or nitrogen) is determined using automatic image analysis. A structured model incorporating a deactivation parameter, $K_{\mathrm{D}}$, relating the effects of total pressure of the system and oxygen content in gas on the cell viability is proposed and used to describe the measured data.

\section{EXPERIMENTAL}

\section{Yeast strain and medium}

The strain Saccharomyces cerevisiae ATCC 32167 was used. It was stored at $-80^{\circ} \mathrm{C}$ in liquid medium with $20 \%(\mathrm{v} / \mathrm{v})$ glycerol. From these stock cultures, agar plates $\left(20 \mathrm{~g} \mathrm{dm}^{-3}\right.$ agar) were inoculated and colonies from the agar plate were used to obtain the inocula for all experiments under hyperbaric conditions. The liquid medium was composed of $0.4 \mathrm{~g} \mathrm{dm}^{-3} \mathrm{MgSO}_{4} .7 \mathrm{H}_{2} \mathrm{O}, 2.0 \mathrm{~g} \mathrm{dm}^{-3}\left(\mathrm{NH}_{4}\right)_{2} \mathrm{SO}_{4}$, $5.0 \mathrm{~g} \mathrm{dm}^{-3} \mathrm{KH}_{2} \mathrm{PO}_{4}, 1.0 \mathrm{~g} \mathrm{dm}^{-3}$ yeast extract, and $5.0 \mathrm{~g} \mathrm{dm}^{-3}$ glucose. The $\mathrm{pH}$ was adjusted to 4.0 prior to autoclaving. Inocula were grown in $250 \mathrm{~cm}^{3}$ shaker flasks containing $50 \mathrm{~cm}^{3}$ of medium at $30^{\circ} \mathrm{C}$ and $120 \mathrm{rpm}$ in an orbital incubator for $15 \mathrm{~h}$.

\section{Batch and fed-batch cultivation}

The experiments were carried out in a $600 \mathrm{~cm}^{3}$ stainless steel reactor (Parr 4563; Parr Instruments, Moline, IL, USA) at a temperature of $30^{\circ} \mathrm{C}$, stirring rate of $400 \mathrm{rpm}$ and a gas flow-rate of $1000 \mathrm{~mL} \mathrm{~min}^{-1}$ (measured at standard conditions of pressure and temperature). Such a large flow-rate volume ratio was chosen after preliminary studies ${ }^{6}$ to assure that the liquid phase was always near saturated on the gas. The pressure of the inlet gas and the regulatory valve in the exit gas line set the operating pressure. The reactor was equipped with a pressure transducer to monitor total internal pressure. In batch experiments, the medium employed in pressurized reactor experiments had the same composition as the medium used for the preparation of inocula. The total batch time was about $8 \mathrm{~h}$. For fed-batch experiments, the medium used had the same composition as the medium employed for the inoculum preparation with the exception of the initial glucose concentration of $60 \mathrm{~g} \mathrm{dm}^{-3}$. The medium was pumped into the reactor using a high-pressure pump (Jasco 880-PU, Essex, UK) with flow rates between 1 and $25 \mathrm{~cm}^{3} \mathrm{~h}^{-1}$ to allow the volumetric cell mass concentration to increase exponentially. The total fedbatch experiment takes $c 30 \mathrm{~h}$. Detailed information about the fed-batch procedure adopted can be found in Ref 7.

\section{Analytical methods}

Cell concentration was estimated through optical density at a wavelength of $620 \mathrm{~nm}$, previously correlated to dry weight determination. Glucose was measured by the 3,5-dinitrosalicylic acid method. ${ }^{8}$ Ethanol was quantified by HPLC (Jasco) with an Organic Acids Chrompack column (Varian, Palo Alto, CA, USA) and an RI detector (830-PU, Jasco). The eluent was $\mathrm{H}_{2} \mathrm{SO}_{4}, 0.01 \mathrm{~N}$, at $0.7 \mathrm{~cm}^{3} \mathrm{~min}^{-1}$ and a column temperature of $40^{\circ} \mathrm{C}$.

Cell viability was determined through the Methylene Blue staining method ${ }^{9}$ and the amounts of viable and non-viable cells were estimated using digital image processing as described in the next section. Although the use of Methylene Blue as an indicator for non-viability is contentious since this method takes into account the membranes' fragility, it is usually employed as a standard in industry and also in scientific procedures, as reported elsewhere. ${ }^{10-12}$

\section{Image analysis procedure}

Image acquisition was conducted in an optical microscope (Axioscop, Zeiss, Germany) with $400 \times$ magnification coupled with a 3CCD DXC-9100P camera (Sony, USA) and linked to a microcomputer by a frame grabber (DT2851, Data Translation Inc, Malboro, USA). The red/green/blue (RGB) color images were decomposed on its blue channel. To take into account irregularities in the background, the resultant decomposed image was divided by its background, an image without cells. A binarization step was performed, employing a threshold value of 0.9 , and an erosion morphological operation to remove small debris was applied. This erosion step was performed with a flat diamond-shaped structuring element ( $R=5$, where $R$ is the distance from the structuring element origin to the points of the diamond). After an image reconstruction step among the eroded image and the binarized one, the number of non-viable cells could be assessed.

To obtain the number of total cells a similar procedure from the above mentioned binarized image was employed using an erosion step with a flat diamond-shaped structuring element $(R=2)$ and an additional hole-fill step after image reconstruction. This image processing, developed with Matlab v 6.1 (The Mathworks Inc, Brazil) package, is fully automated. Performing such analysis, an average deviation of less than $5 \%$ is obtained when compared with the traditional manual counting.

\section{Model formulation}

The conventional model structure employed in mathematical representations of macro-kinetic variables in biological systems was the starting point for the formulation of the model herein proposed. The influence of 
environmental conditions in cell viability was incorporated by the assumption that the total cell population is divided into two categories, viable and non-viable cells, which are inactive or non-growing but nevertheless intact cells. This means that cellular lysis is not considered in this formulation as the experimental results obtained by Lange $e t a l^{13}$ show that $S$ cerevisiae cells remain intact at pressures up to $1.8 \mathrm{MPa}$.

As this work presents experimental data for cell viability, it is possible to show that the viability $(\gamma)$, calculated as a ratio between viable and total cells $\left(X_{\mathrm{V}} / X_{\mathrm{t}}\right)$, might not be constant during the experiments, depending on the environment applied. The loss of viability is given by an additional parameter, $K_{\mathrm{D}}$, which assumes that the rate of transformation into the non-viable form is directly proportional to the concentration of viable cells. This parameter relates the influence of two opposite phenomena: the higher oxygen availability in pressurized systems and the baric and oxidative stresses.

The model is composed of four ordinary differential equations (ODEs) relating the kinetic rates for cell growth, cell viability, substrate consumption and product formation for both batch and fed-batch systems, as described by:

$$
\begin{aligned}
\frac{\mathrm{d} X_{\mathrm{V}}}{\mathrm{d} t} & =-\frac{F}{V} X_{\mathrm{V}}+\mu_{\mathrm{R}}\left(\frac{S}{K_{\mathrm{S}}+S}\right) X_{\mathrm{V}}-K_{\mathrm{D}} X_{\mathrm{V}} \\
\frac{\mathrm{d} X_{\mathrm{NV}}}{\mathrm{d} t} & =-\frac{F}{V} X_{\mathrm{NV}}+K_{\mathrm{D}} X_{\mathrm{V}} \\
\frac{\mathrm{d} S}{\mathrm{~d} t} & =\frac{F}{V}\left(S_{\mathrm{f}}-S\right)-\frac{1}{Y_{\mathrm{X} / \mathrm{S}}} \mu_{\mathrm{R}}\left(\frac{S}{K_{\mathrm{S}}+S}\right) X_{\mathrm{V}} \\
\frac{\mathrm{d} P}{\mathrm{~d} t} & =-\frac{F}{V} P+Y_{\mathrm{P} / \mathrm{X}} \mu_{\mathrm{R}}\left(\frac{S}{K_{\mathrm{S}}+S}\right) X_{\mathrm{V}}
\end{aligned}
$$

The solution of the system of ordinary differential equations and parameters evaluation was performed using Matlab v 6.1 (The Mathworks Inc). The implicit third order Runge-Kutta method for non-stiff ODEs was applied to find the solution of the system. The estimated parameters, $\mu_{\mathrm{R}}, K_{\mathrm{s}}$ and $K_{\mathrm{D}}$, were found by means of the optimization procedure joining the elements of Nelder-Mead simplex procedures. The yields, namely $Y_{\mathrm{X} / \mathrm{S}}$ and $Y_{\mathrm{P} / \mathrm{X}}$, were directly calculated from the experimental data as averages over a given fermentation, this being the approach employed in most biological systems.

\section{RESULTS AND DISCUSSION}

The model parameters values obtained for the various operational conditions studied are presented in Table 1. Results from a typical model are presented in Figs 1 and 2, for a batch and a fed-batch system respectively. To verify the statistical significance of the parameters, analyses through $t$-Student distribution were performed with $95 \%$ confidence. In all cases, the hypothesis of the $K_{\mathrm{D}}$ parameter equal to zero was rejected, indicating that they are significant. The proposed model provides a good description of the experimental data available not only in terms of $X_{\mathrm{t}}$, $P$ and $S$ but allowing also the determination of the viability profile along the experiments, as shown in Fig 3.

The viabilities reported in Table 2 show that often the fraction of viable cells towards the end of the fermentation is small, as displayed in Fig 3(a), and that in some cases the viability has non-monotonical behavior during the fermentation, as the results presented in Fig 3(b) clearly demonstrate. It means

Table 1. Model estimated parameters for the batch and fed-batch systems studied

\begin{tabular}{lcrcccc}
\hline & $\begin{array}{c}P_{\mathrm{R}} \\
\text { Experiment }\end{array}$ & $\mathrm{MPa})$ & $\begin{array}{c}\mathrm{EtOH} \\
\%\end{array}$ & $\begin{array}{c}\mu_{\mathrm{R}} \\
\left(\mathrm{g} \mathrm{dm}^{-3}\right)\end{array}$ & $\begin{array}{c}K_{\mathrm{S}} \\
\left(\mathrm{h}^{-1}\right)\end{array}$ & $\begin{array}{c}K_{\mathrm{D}} \\
\left(\mathrm{g} \mathrm{dm}^{-3}\right)\end{array}$ \\
\hline Batch & 0.1 & 0 & 1.60 & 0.38 & 1.05 & 0.0152 \\
Batch & 0.6 & 0 & 1.78 & 0.29 & 0.98 & 0.0140 \\
Batch & 0.1 & 21 & 0.86 & 0.43 & 0.98 & 0.0351 \\
Fed-batch & 0.1 & 21 & 9.42 & 0.54 & 0.25 & 0.0470 \\
Batch & 0.6 & 21 & 0.96 & 0.54 & 2.63 & 0.0090 \\
Fed-batch & 0.6 & 21 & 5.74 & 0.29 & 0.43 & 0.0299 \\
Fed-batch & 1.0 & 21 & 4.51 & 0.46 & 0.41 & 0.0401 \\
Fed-batch & 1.5 & 21 & 1.51 & 0.08 & 2.17 & 0.0425 \\
Fed-batch & 0.1 & 100 & 5.35 & 0.44 & 0.59 & 0.0544 \\
Batch & 0.3 & 100 & 0.11 & 0.21 & 1.90 & 0.0254 \\
Fed-batch & 0.3 & 100 & 1.08 & 0.03 & 0.89 & 0.0397 \\
Batch & 0.5 & 100 & 0.00 & 0.06 & 4.85 & 0.0075 \\
Fed-batch & 0.5 & 100 & 1.12 & 0.05 & 0.86 & 0.0316 \\
\hline
\end{tabular}

$t_{\text {final }}=7.5 \mathrm{~h}$ for batch experiments and $t_{\text {final }}=27 \mathrm{~h}$ for fed-batch.
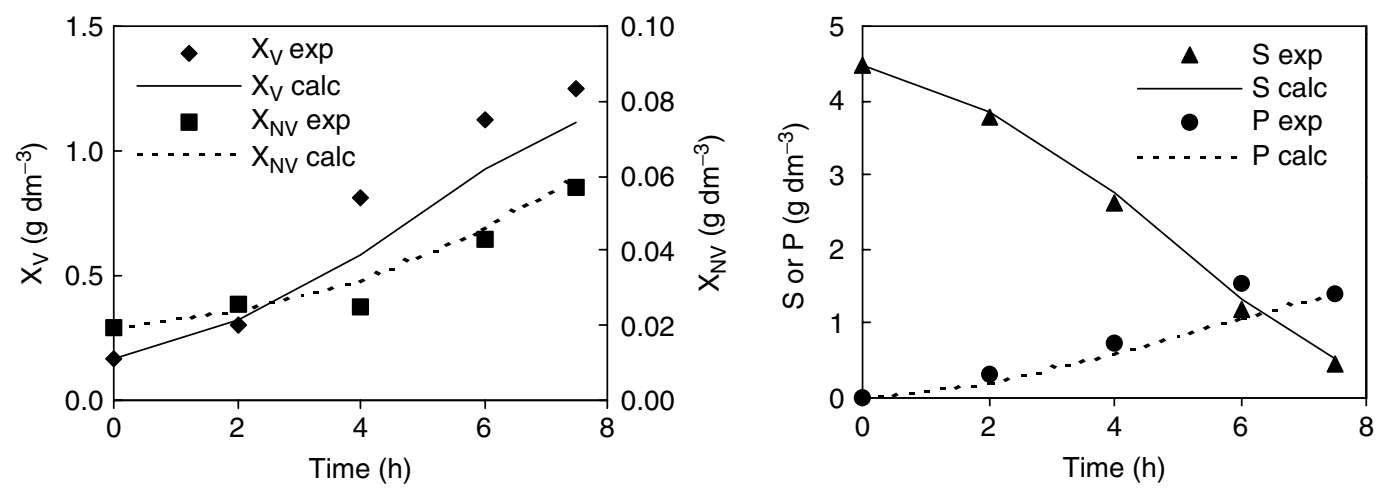

Figure 1. Kinetic data and model description for a batch experiment with air at 0.6 MPa. 

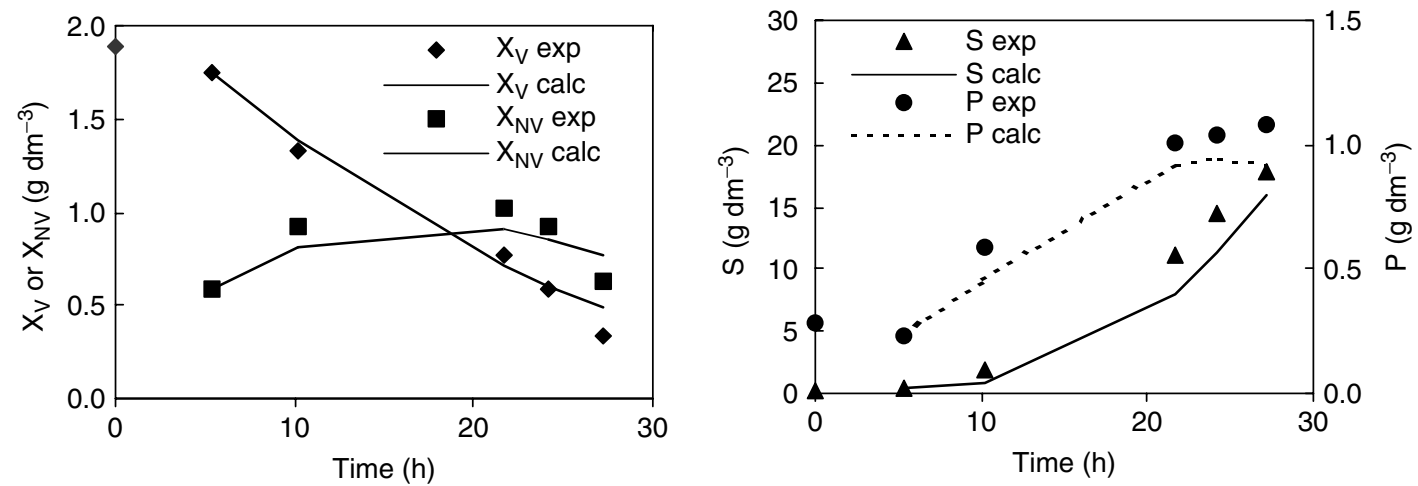

Figure 2. Kinetic data and model description for a fed-batch experiment with $\mathrm{O}_{2}$ at $0.3 \mathrm{MPa}$.
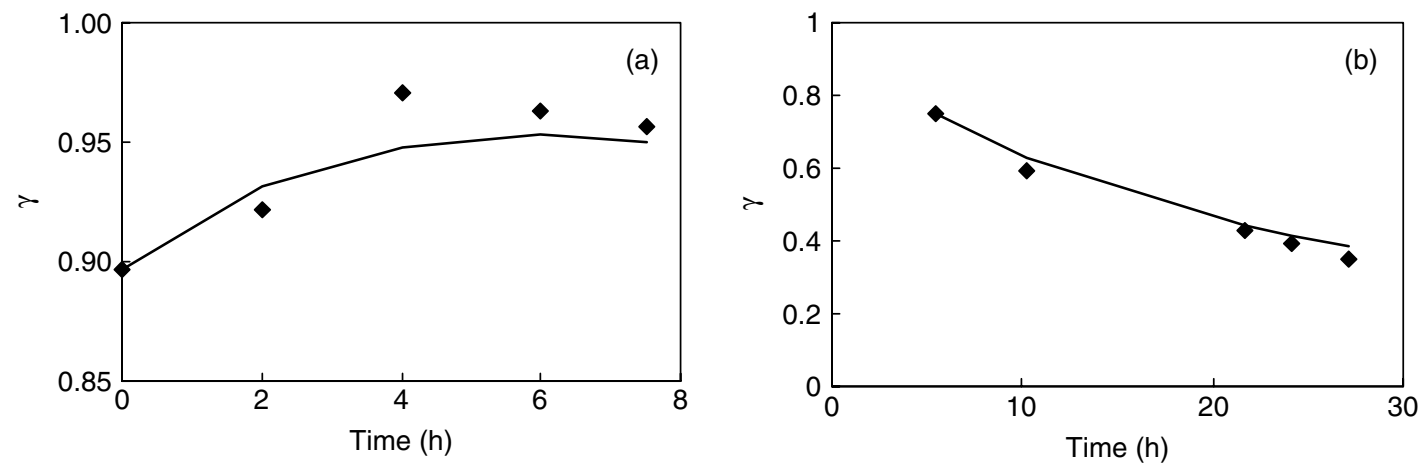

Figure 3. Viability profiles for the (a) batch system with air at $0.6 \mathrm{MPa}$ and (b) fed-batch system with $\mathrm{O}_{2}$ at $0.3 \mathrm{Mpa}$.

that the assumption made by Oliveira $e t a l^{4}$ that the cell viability is constant during a fermentation is possible but, in general, not correct.

The experimental data herein obtained for ethanol production are displayed in Table 1. As can be noticed, the final ethanol concentrations get lower with pressure increase under fed-batch conditions $\left(9.4 \mathrm{~g} \mathrm{dm}^{-3}\right.$ for air at $0.1 \mathrm{MPa}$ and $1.5 \mathrm{~g} \mathrm{dm}^{-3}$ for air at $1.5 \mathrm{MPa}$; $5.4 \mathrm{~g} \mathrm{dm}^{-3}$ for pure oxygen at $0.1 \mathrm{MPa}$ and $1.1 \mathrm{~g} \mathrm{dm}^{-3}$ for pure oxygen at $0.5 \mathrm{MPa}$ ) due to a more oxidative atmosphere predominating in an aerobic metabolism when air or pure oxygen was applied. It must be considered that a control experiment (at atmospheric

Table 2. Values obtained for the experimental and calculated initial and final viabilities

\begin{tabular}{lcrccc}
\hline Experiment & $P_{\mathrm{R}}(\mathrm{MPa})$ & $\% \mathrm{O}_{2}$ & $\gamma_{\text {ini,exp }}$ & $\gamma_{\text {final, exp }}$ & $\gamma_{\text {final,calc }}$ \\
\hline Batch & 0.1 & 0 & 0.92 & 0.94 & 0.90 \\
Batch & 0.6 & 0 & 0.93 & 0.94 & 0.93 \\
Batch & 0.1 & 21 & 0.95 & 0.86 & 0.86 \\
Fed-batch & 0.1 & 21 & 0.85 & 0.66 & 0.65 \\
Batch & 0.6 & 21 & 0.90 & 0.96 & 0.95 \\
Fed-batch & 0.6 & 21 & 0.67 & 0.78 & 0.77 \\
Fed-batch & 1.0 & 21 & 0.76 & 0.65 & 0.70 \\
Fed-batch & 1.5 & 21 & 0.75 & 0.57 & 0.57 \\
Fed-batch & 0.1 & 100 & 0.89 & 0.65 & 0.64 \\
Batch & 0.3 & 100 & 0.92 & 0.85 & 0.86 \\
Fed-batch & 0.3 & 100 & 0.75 & 0.35 & 0.38 \\
Batch & 0.5 & 100 & 0.92 & 0.89 & 0.88 \\
Fed-batch & 0.5 & 100 & 0.70 & 0.35 & 0.35 \\
\hline
\end{tabular}

$t_{\text {final }}=7.5 \mathrm{~h}$ for batch experiments and $t_{\text {final }}=27 \mathrm{~h}$ for fed-batch. pressure) was always carried out to by-pass crossing effects between baric and other types of stress.

Yeast cells have developed a panel of stress responses (transient) and adaptation mechanisms (long-term response) to cope with deleterious effects of ethanol. Results obtained by Alexandre et $a l^{14}$ showed that superoxide dismutase (SOD) genes are not induced after $30 \mathrm{~min}$ ethanol shock $(8 \% \mathrm{v} / \mathrm{v})$. In addition, the growth of $S$ cerevisiae under active oxygenation increased cell viability to subsequent ethanol stress in comparison to growth under anaerobiosis, according to Pina et $a l^{15}$ These results indicate that for $S$ cerevisiae, the presence of oxygen or of certain compounds added exogenously to the growth medium could enhance the tolerance to ethanol.

For a gaseous solute such as oxygen and azote the relationship between its concentration in the gas and liquid phases can be given by the Henry's law that in its most generic form for solute $i$ is:

$$
f_{i}=\varphi_{i} y_{i} P_{\mathrm{R}}=H_{i, \text { water }} x_{i}
$$

At the moderate pressures used on this study, Henry's constant, $H_{i}$, can be considered pressure independent and to a fair approximation the fugacity coefficient can be taken as a unitary value. The gas dissolved in the liquid phase, at a constant temperature of $30^{\circ} \mathrm{C}$ used in this work, is thus only dependent on the nature and pressure of the gas, and gas phase composition. For the case of air the presence of nitrogen will not affect the solubility of oxygen in the aqueous phase, due to 
their low solubility on water, but will only affect the partial pressure, $y_{i} P_{\mathrm{R}}$, in the gas phase. The solubility of oxygen in water will thus be similar for pure oxygen at $0.1 \mathrm{MPa}$ and air at $0.5 \mathrm{MPa}$. The influence of the gas' nature will be translated by the values of Henry's constant with $11.29 \mathrm{MPa}$ for nitrogen and 10.64 for oxygen at $30^{\circ} \mathrm{C}^{16}$ in pure water. The presence of sugar and salts will contribute to somewhat reduce these solubilities but this will not affect the validity of the discussion and results reported here. From eqn (5) it can be seen that the oxygen dissolved in the aqueous phase is directly proportional to the partial pressure of the oxygen in the gas phase. The rate of oxygen transfer from the gas to the liquid phase is given by:

$$
N_{\mathrm{A}}=K_{\mathrm{L}} a\left(x-x^{*}\right)
$$

Although the contact area, $a$, will be reduced by the pressure, the mass transfer will increase with pressure because the mass transfer coefficient, $K_{\mathrm{L}}$, is fairly insensitive to pressure changes and the effect of the pressure increasing is more pronounced on $x^{*}$ than over $a$. While $x^{*}$ will increase directly with pressure the contact area will be reduced by a similar factor but affected by the $2 / 3$ power. The gas transfer rate is thus favored at high pressures. The conditions of aeration adopted in this work were chosen to guarantee that the liquid phase was always nearly saturated. In the following discussion it will then be assumed that the liquid phase is close to equilibrium and that the oxygen availability in the liquid phase can be taken as proportional to its partial pressure in the gas phase.

In view of these considerations, the $K_{\mathrm{D}}$ values obtained reveal a complex pattern relating the opposite influences of the increase in oxygen content and pressure. In fact, the pressure increase leads to a favorable effect in cell viability until pressures of about 1.0 MPa. This is related to an increment in oxygen availability at high pressure. It was shown by Belo ${ }^{6}$ that up to $1.0 \mathrm{MPa}$ the intracellular ATP concentration increases, driving the cell metabolism to an oxidative regime, which is more energy efficient. However the higher level of oxygen also provokes an oxidative stress to the cells, expressed by the activity of anti-oxidant enzymes such as superoxide dismutase and catalase. ${ }^{6}$ These enzymes act as a cellular defense against the oxygen reactive species.

At pressures higher than $1.0 \mathrm{MPa}$, the advantages of the increment in oxygen content are offset by the oxidative stress. Bartlett ${ }^{17}$ described a negative effect of the pressure in cell viability, mostly due to a pressure effect on the cell membrane reducing its fluidity but for the range of pressures herein used, the effects of oxygen partial pressure must be the main cause of cell damage. For anaerobic conditions an increase of $\mathrm{N}_{2}$ pressure did not affect cell viability at pressures up to $0.6 \mathrm{MPa}$. In fact, Coelho et al ${ }^{18}$ described no influence on cell growth and a slightly enhanced ethanol production, not disturbing cell metabolism, under the same experimental conditions.
Based on these process characteristics, a function is proposed to correlate the influences of the increase of both oxygen content and pressure on $K_{\mathrm{D}}$, given by:

$$
K_{\mathrm{D}}=\frac{a y_{\mathrm{O}_{2}}}{\left(1+b y_{\mathrm{O}_{2}}\right)}\left[\exp \left(-c P_{\mathrm{R}}\right)+d P_{\mathrm{R}}\right]
$$

The first term in eqn (7) expresses the effect of the oxygen content in the gas phase as the nature of the gas is crucial for the pressure effect on the yeast activity. Under aerobic conditions, it can be assumed that oxygen toxicity is the major cause of cell damage and not the total pressure itself. ${ }^{18}$ The second and third terms deal with the effect of pressure, with the former giving the increase in oxygenation and the latter the oxidative stress. The total pressure is an important parameter to take into account in bioreactor design and operation, since it affects oxygen partial pressures.

The parameters in eqn (7) were estimated to adjust the $K_{\mathrm{D}}$ values for both batch and fed-batch conditions presented in Table 1 . The $a, b, c$ and $d$ parameter values obtained are respectively 2.24, 0.45, 2.46 and 0.51 . Thus, such correlation can be used to estimate the cell viability under different oxygen content and pressure conditions helping to assure consecutive reutilization of biomass in some industrial processes.

\section{CONCLUSIONS}

An image analysis procedure was developed for the automated discrimination between viable and nonviable cells in each experimental condition. The main advantage of using such a procedure is to increase the number of objects analyzed, leading to a more representative data analysis.

A modeling approach is proposed to describe the effects of barometric pressures of different gases (air, oxygen or nitrogen) on the loss of viability of $S$ cerevisiae under batch and fed-batch conditions. This approach allowed the description of the viability profile during the experiments and show that the common assumption that cell viability is constant during the fermentation may hold in some cases but, in general, is not correct. The model proposed and the function used to correlate the influences of the increase of both oxygen content and pressure on $K_{\mathrm{D}}$ can be used to predict the cells viability in industrial systems.

\section{ACKNOWLEDGMENTS}

MAZ Coelho is grateful for the financial support given by CAPES and CNPq (Brazil) for this work.

\section{REFERENCES}

1 Bizukocj $M$ and Ledakowicz S, Morphologically structured model for growth and citric acid accumulation by Aspergillus niger. Enzyme and Microbial Technology 32:268-281 (2003).

2 Henson MA, Dynamic modeling and control of yeast cell populations in continuous biochemical reactors. Computers $\mathcal{E}$ Chemical Engineering 27:1185-1199 (2003). 
3 Facciotti MCR and Schmidell W, The new concept of minimum cell viability and its consequences on bioprocess design and operation. Braz f Chem Eng 12:22-31 (1995).

4 Oliveira SC, De Castro HF, Visconti AES and Giudici R, Scaleup effects on kinetic parameters and on predictions of a yeast recycle continuous ethanol fermentation model incorporating loss of cell viability. Bioprocess Engineering 23:51-55 (2000).

5 Coutinho JAP and Xavier AMRB, A model for micro/ultrafiltration cell deactivation in cell recycle reactors. $\mathcal{F}$ Chem Technol Biotechnol 75:315-319 (2000).

6 Belo I, Study of the effect of pressure on the physiologic behaviour of microorganisms. PhD thesis, Universidade do Minho, (1999). (in Portuguese).

7 Belo I, Pinheiro R and Mota M, Fed-batch cultivation of Saccharomyces cerevisiae in a hyperbaric bioreactor. Biotechnol Prog 19:665-671 (2003).

8 Miller GE, Use of dinitrosalicylic acid reagent for determination of reducing sugar. Anal Chem 31:426-428 (1959).

9 Lange H, Bavouzet JM, Taillandier P and Delorme C, Systematic error and comparison of four methods for assessing the viability of Saccharomyces cerevisiae. Biotechnol Tech 7:223-228 (1993).

10 Alfenore S, Cameleyre X, Benbadis L, Bideaux C, Uribelarrea J-L, Goma G, Molina-Jouve C and Guillouet SE, Aeration strategy: a need for very high ethanol performance in Saccharomyces cerevisiae fed-batch process. Appl Microbiol Biotechnol 63:537-542 (2004).
11 Calado CRC, Mannesse M, Egmond M, Cabral JMS and Fonseca LP, Production of wild-type and peptide fusion cutinases by recombinant Saccharomyces cerevisiae MM01 strains. Biotechnology and Bioengineering 78:692-698 (2002).

12 Domingues L, Lima $\mathrm{N}$ and Teixeira JA, Alcohol production from cheese whey permeate using genetically modified flocculent yeast cells. Biotechnology and Bioengineering 72:507-514 (2001).

13 Lange H, Taillandier P and Riba JP, Effect of high shear stress on microbial viability. F Chem Technol Biotechnol 76:501-505 (2001).

14 Alexandre H, Ansanay-Galeote V, Dequin S and Blondin B, Global gene expression during short-term ethanol stress in Saccharomyces cerevisiae. FEBS Letters 498:98-103 (2001).

15 Pina C, Santos C, Couto JA and Hogg T, Ethanol tolerance of five non-Saccharomyces wine yeasts in comparison with a strain of Saccharomyces cerevisiae - influence of different culture conditions. Food Microbiology 21:439-447 (2004).

16 Prausnitz JM, Lichtenthaler RN and Azevedo EG, Molecular Thermodynamics of Fluid Phase Equilibria, 3rd edn. Prentice Hall, New Jersey, USA (1999).

17 Bartlett DH, Microbial life at high pressures. Science Progress 76:476-496 (1992)

18 Coelho MAZ, Belo I, Pinheiro R, Amaral, AL, Mota M, Coutinho JAP and Ferreira EC, Effect of hyperbaric stress on yeast morphology: study by automated image analysis. Applied Microbiol Biotechnol 66:318-324 (2004). 